\title{
Uterine Inversion: An Uncommon Progressive Forme of Leiomyosarcoma Uterine: Case Report and Review of Literature
}

\author{
Apollinaire Gninlgninrin Horo ${ }^{{ }^{*}}$, Kacou Edele Aka ${ }^{1}$, Minata Fomba ${ }^{1}$, Abdoul Koffi ${ }^{1}$, \\ N'guessan Alphonse Aman², Mohamed Kouyate², Konan Séni', Benjamin Effi ${ }^{3}$, \\ Koné Mamourou ${ }^{1}$ \\ ${ }^{1}$ Gynaecology Obstetrics Department, Teaching Hospital of Yopougon, Abidjan, Côte d'Ivoire \\ ${ }^{2}$ Anatomy and Pathology Department, Teaching Hospital of Treicvhville, Abidjan, Côte d'Ivoire \\ ${ }^{3}$ Histopathology Department, Teaching Hospital of Treichville, Abidjan, Côte d'Ivoire \\ Email: "apollinaire.horo@univ-fhb.edu.ci
}

Received 8 January 2016; accepted 26 February 2016; published 29 February 2016

Copyright (C) 2016 by authors and Scientific Research Publishing Inc.

This work is licensed under the Creative Commons Attribution International License (CC BY).

http://creativecommons.org/licenses/by/4.0/

cc) (i) Open Access

\begin{abstract}
Uterine leiomyosarcoma (LMS) is a rare uterine malignancy that represents approximately $1 \%$ of uterine cancers. The nonspecific symptoms cause difficulties in the diagnostic, prognostic and therapeutic. We report an unusual progressive form, with a uterine inversion of LMS fundal externalized out of the vulva in a patient of 48 years old premenopausal.
\end{abstract}

Keywords

Leiomyosarcoma, Uterine Inversion, Externalized out of the Vulva

\section{Introduction}

The carcinosarcoma (CS) uterine are rare tumors and represent $2 \%$ to $4 \%$ of all malignancies of the uterus [1]. They are characterized on one hand, by a significant histopathological and clinical diversity and an aggressive nature and poor prognosis on the other [2]. Regarding histopathological forms, we distinguish leiomyosarcomas (LMS), stromal tumors and endometrial sarcoma. The symptomatology is nonspécific with the consequences

${ }^{*}$ Corresponding author.

How to cite this paper: Horo, A.G., Aka, K.E., Fomba, M., Koffi, A., Aman, N.A., Kouyate, M., Séni, K., Effi, B. and Mamourou, K. (2016) Uterine Inversion: An Uncommon Progressive Forme of Leiomyosarcoma Uterine: Case Report and Review of Literature. Open Journal of Obstetrics and Gynecology, 6, 144-148. http://dx.doi.org/10.4236/ojog.2016.62018 
difficulties of diagnostic, prognostic and therapeutic. The current evolution is towards an extension of the tumor to the pelvis, abdomen or remotely. We report a rare clinical progressive form, a LMS externalized out of the vulva with a uterine inversion of the fundus among premenopausal patient 48 years.

\section{Case Report}

A premenopausal woman of 48 years old, multiparous, with a body mass index of $37,8 \mathrm{~kg} / \mathrm{m}^{2}$ who consulted for uterine bleeding, which evolved over six months with a clinical impact in type of dizziness and dyspnea of effort with a hemoglobin of $6.5 \mathrm{~g} / \mathrm{dl}$. His medical history was featureless. She had a polymyomatous uterine asymptomatic found by ultrasound since three years.

On examination, the patient had abdominal pelvic mass at a finger's breadth below the navel is about $18 \mathrm{~cm}$. Speculum examination highlighted a tumor greater than $5 \mathrm{~cm}$ of budding irregular indurated axis non-friable and bleeding on contact with the cervix associated with malodorous discharge. A tumor biopsy was performed. Histological examination revealed a malignant tumor proliferation of smooth muscle cells. They had found an LMS cervix. As part of the classification, the computed tomography (CT) in the absence of a magnetic resonance imaging (MRI) objectified malignant cervical tumor process $83.9 \times 70 \mathrm{~mm}$ with an extension at body uterine, vaginal and with the posterior wall of the bladder.

The diagnosis of cervical LMS locally advanced beyond the stage surgery was chosen immediately and neoadjuvant radiochemotherapy was proposed after a multidisciplinary consultation. This therapeutic proposal has been not made possible by inadequate financial coverage. The patient was lost to sight. She returned three months later for a consultation organ descent associated with bleeding. A clinical examination brought to light a tumor necrosis externalized out of the vulva.

An examination under general anesthesia, allowed us to conclude that the LMS inverted fundus (Figure 1). A total hysterectomy associated with bilateral annexectomy was performed vaginally and allowed to identify uterine LMS stage IB like the final diagnosis (Figure 2). The final histological results of the surgical specimen confirmed an LMS fundal measuring $11 \mathrm{~cm}$ in major axis and grade III according to the classification of FNCLCC SBR 2 (Figure 3, Figure 4). The postoperative period was featureless. The patient survival at 6 months showed no clinical sign and resumed his daily activities.

\section{Discussion}

Uterine LMS is a rare malignant tumor with an estimated annual incidence of 0.64 per 100000 women [3]. Pelvic irradiation was considered like a risk factor des CS also called uterine tumors Malignant Mixed Mullerian (WMMMI) in 10\% - 25\% of cases. Other risk factors have been identified as the black race, the field of hyperoestrogenemia, obesity and the use of long-term adjuvant tamoxifen in women with breast cancer. By cons, data

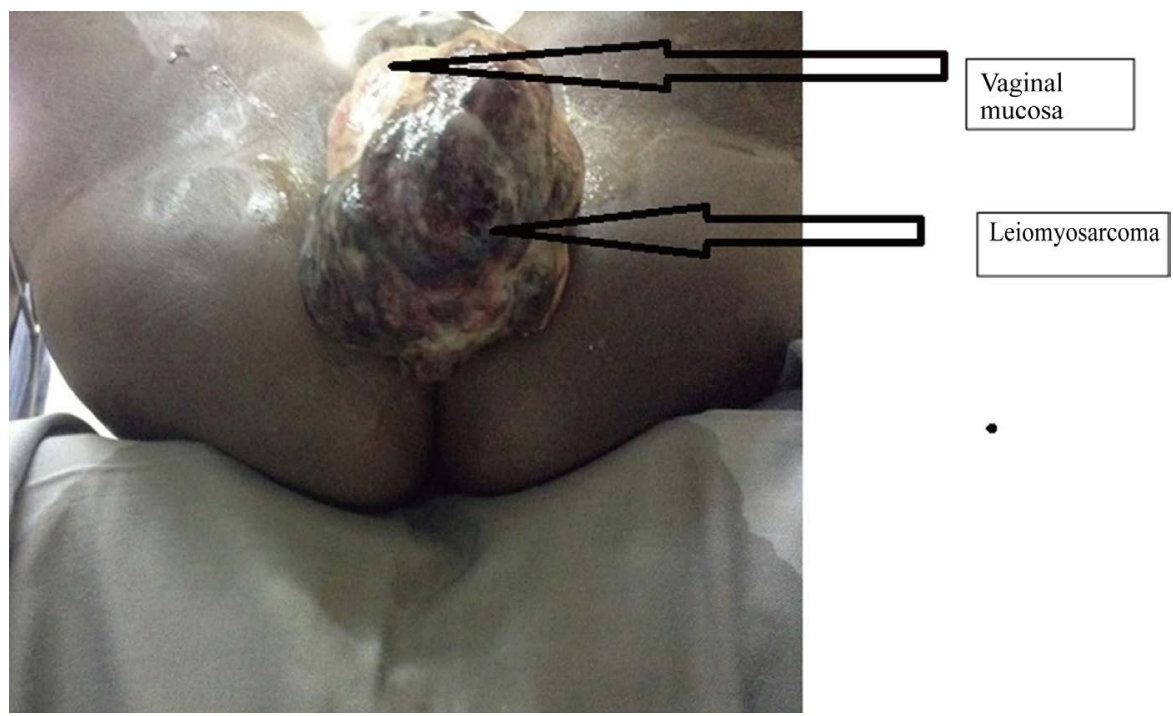

Figure 1. Sarcoma of body uterine inverted and vaginal prolapsed. 


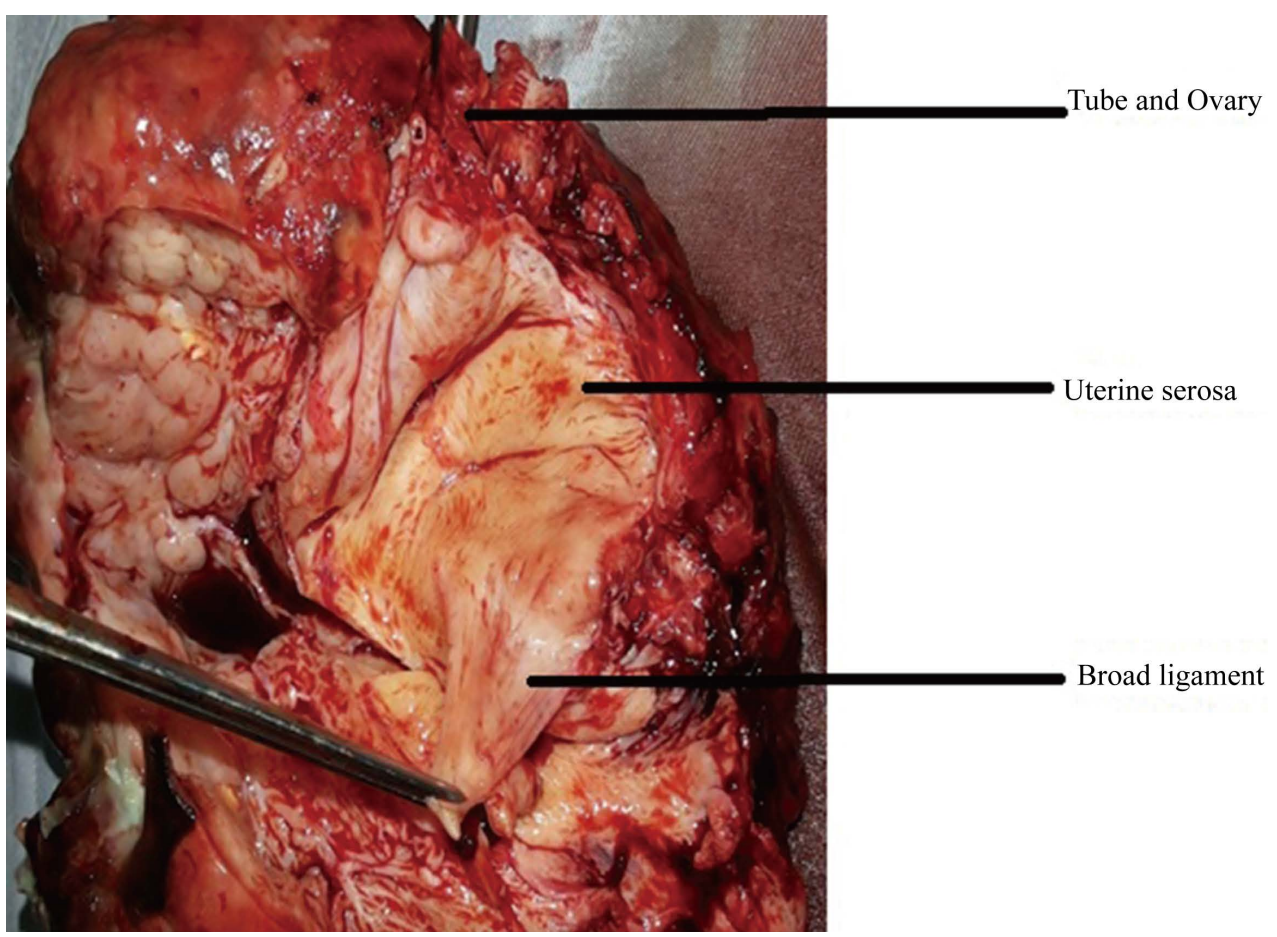

Figure 2. Total hysterectomy associated with bilateral annexectomy.

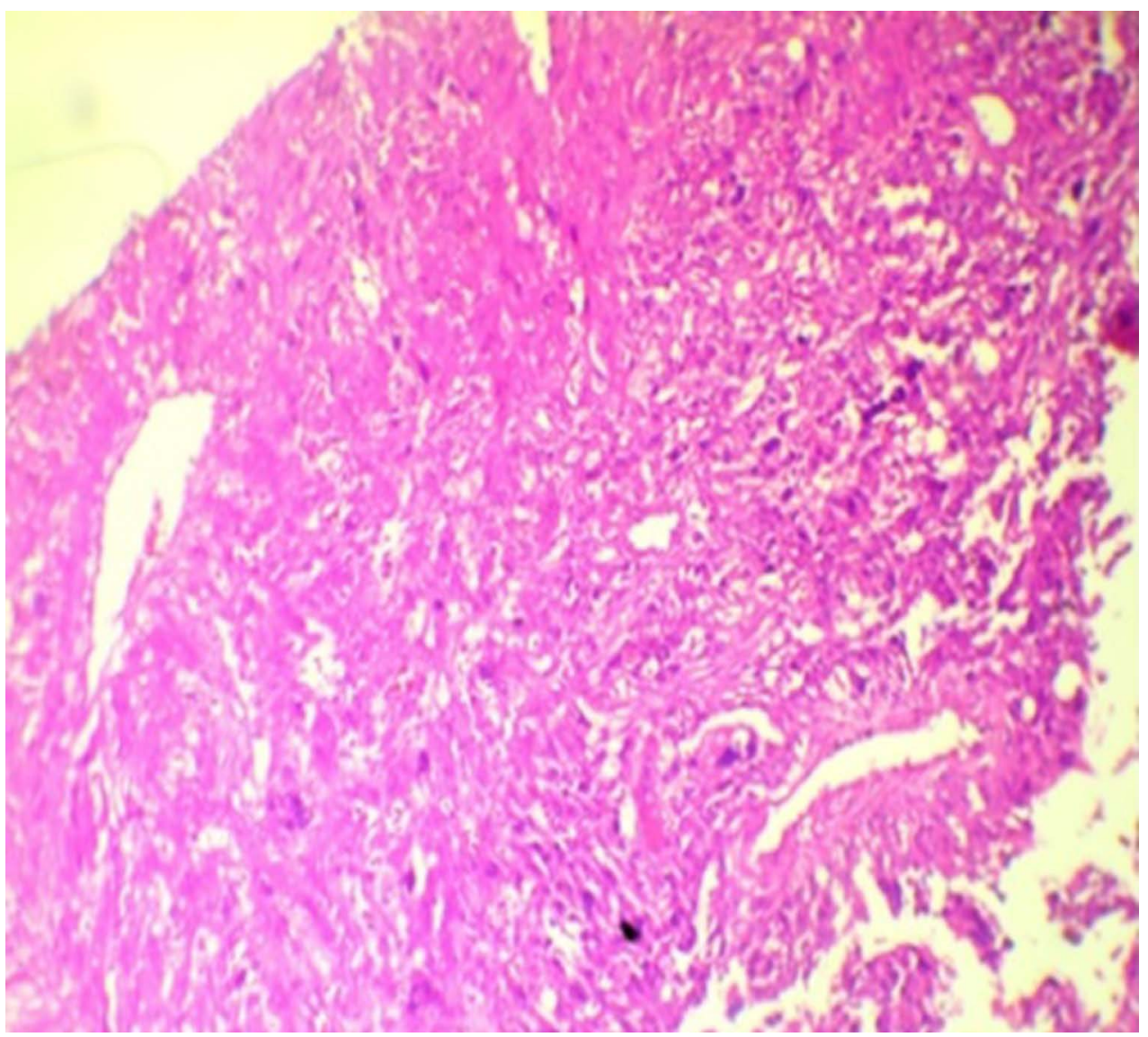

Figure 3. Microscopic slide uterine leiomyosarcoma magnification 100×. 


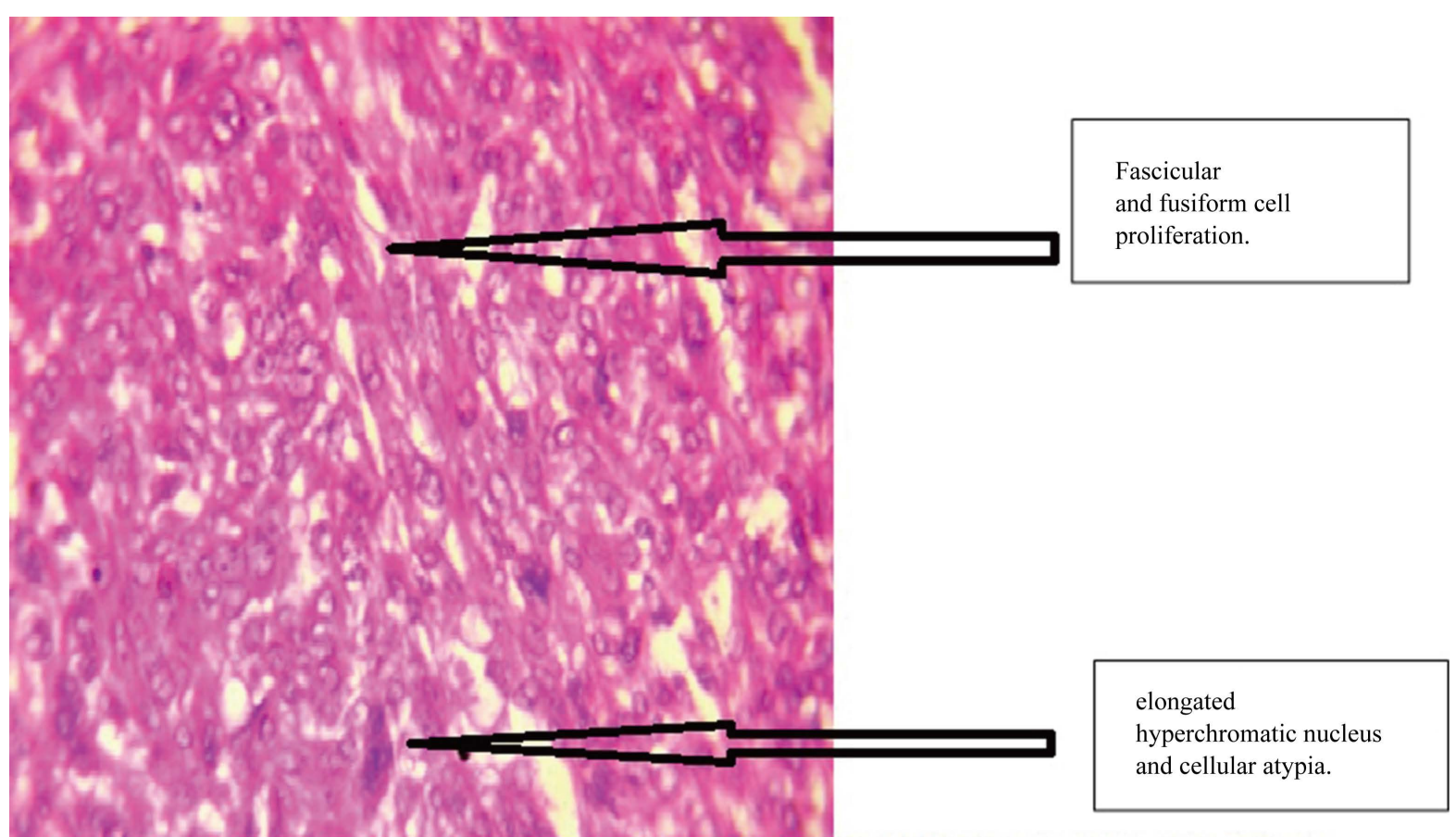

Figure 4. Microscopic slide uterine leiomyosarcoma magnification 100×.

on parity, early puberty and menopause are inconclusive [2] [4]. In outside black and obesity characters, we have not found other risk factors such as pelvic irradiation and chronic taking tamoxifen in the patient. The CS age of onset is variable. For G. Khatib et al. [5], the average age of patients was 53.7 years, while D'angelo E. et al. [6] noted that most women had women over 40 years.

The symptomatology was dominated by abnormal vaginal bleeding (56\%), pelvic mass (54\%) and pelvic pain (22\%). The signs differ little from that of uterine fibroids. Malignant degeneration of uterine fibroids is rare with a time of variable appearance, not established to date. So far, the mechanisms underlying oncogenic explaining the transition from the LMS leiomyoma remain inexplicable [7]. LMS often coexist within a fibroid uterus and about $0.5 \%$ of hysterectomy for uterine fibroids rooms are carriers of LMS. The presence of LMS in our patient would it be related or unrelated to the presence of fibroid cores? Malignant transformation of uterine fibroids is still debated, and if it happens, it would be exceptional [8]. Furthermore, in addition to these findings clinic, we discover after a gynecolgical exam a mass of more than $5 \mathrm{~cm}$ indurated irregular burgeoning non-friable and bleeding on contact. In the series of Hassini et al., Three patients had tumor necrotic and friable given birth by collar [9]. This is a uncommon clinical form which can be mistakenly considered a cervical tumor even though it has already been described by some authors as the LMS are seen elsewhere in the pelvis namely the cervix and bladder [3].

The few specific imaging techniques are used to assess the local extent of the tumor to guide surgery or excluded in the case of unresectable tumors. In our series, CT had found a uterine LMS locally advanced and unresectable immediately. The second goal of imaging techniques is to look for metastases. CT is usually sufficient, but MRI and positron emission tomography scanning are advocated by some authors for the postoperative follow-up and differentiation between CS and benign tumors [1] [2]. Pending a multidisciplinary care, the tumor continue evolving as the patient was premenopausal. The weight of the tumor measuring $11 \mathrm{~cm}$ and topography at the uterine fundus eventually reversed the uterus and externalized out of the vulva.

The patient underwent a non-conservative hysterectomy vaginal and histological examination of the surgical specimen confirmed the diagnosis. Treatment usually consists of a total hysterectomy. Bilateral oophorectomy and pelvic lymph node dissection and para-aortic are not recommended because the involvement of lymph nodes is seen in less than 3\% of cases [10]. Bilateral oophorectomy is recommended after menopause [1] [11]. Radiation therapy and/or pelvic adjuvant chemotherapy give the same results in terms of five-year survival without recurrence [12] [13]. 
The results of the multivariate analysis Khatib G have identified age, tumor stage, lymph vascular invasion of space and lymphadenectomy as independent prognostic factors affecting survival without disease. The discovery stage of the tumor was identified as alone as an independent prognostic factor for overall survival [5]. Thus, the rate of five-year survival is $50 \%$ to $55 \%$ for stage I and $8 \%$ to $12 \%$ for stage II, III and IV [14]. Six months after surgery, the patient had no clinical signs and resumed his daily activities.

\section{Conclusion}

Uterine LMS is a rare and aggressive malignancy. This is a misleading pathology with a clinical and para-clinical polymorphism. The diagnosis is histological. Treatment is primarily surgical. The discovery stage of the tumor affects the treatment and prognosis. Facing any intravaginal tumor, we must think and do biopsies for early treatment for avoid this progressive and discomfort form.

\section{References}

[1] Dorigo, O. and Annekathryn, G. (2006) Premalignant \& Malignant Disorders of the Uterine Corpus. In: De Cherney, A.H., Nathan, L., Goodwin, M.T. and Laufer, N., Eds., Current Diagnosis \& Treatment Obstetrics \& Gynecology, 10th Edition, The McGraw-Hill Companies, New York.

[2] Schorge, J.O. (2008) Uterinesarcoma. In: Schorge, J.O., Schaffer, J.I., Halvorson, L.M., Hoffman, B.L., Bradshaw, K.D. and Cunningham, F.G., Eds., Williams Gynecology, The McGraw-Hill Companies, New York.

[3] Corcoran, S., Hogan, A.M., Nemeth, T., Bennani, F., Sullivan, F.J., Khan, W., et al. (2012) Isolated Cutaneous Metastasis of Uterine Leiomyosarcoma: Case Report and Review of Literature. Diagnostic Pathology, 7, 85. http://dx.doi.org/10.1186/1746-1596-7-85

[4] Bergman, L., Beelen, M.L., Gallee, M.P., Hollema, H., Benraadt, J. and van Leeuwen, F.E. (2000) Risk and Prognosis of Endometrial Cancer after Tamoxifen for Breast Cancer. Comprehensive Cancer Centres ALERT Group Assessment of Liver and Endometrial Cancer Risk Following Tamoxifen. Lancet, 356, 881-887. http://dx.doi.org/10.1016/S0140-6736(00)02677-5

[5] Khatib, G., Guzel, A.B., Gulec, U.K., Gumurdulu, D., Vardar, M.A. and Altintas, A. (2014) Clinic Pathological Features and Prognostic Factors of the Uterinesarcomas: 20 Years of Experience at Cukurova University. European Journal of Gynaecological Oncology, 35, 646-654.

[6] D’Angelo, E. and Prat, J. (2010) Uterinesarcomas: A Review. Gynecologic Oncology, 116, 131-139. http://dx.doi.org/10.1016/j.ygyno.2009.09.023

[7] Di Luigi, G., D’Alfonso, A., Patacchiola, F., Di Stefano, L., Palermo, P. and Carta, G. (2015) Leiomyosarcoma: A Rare Malignant Transformation of a Uterine Leiomyoma. European Journal of Gynaecological Oncology, 36, 84-87.

[8] Wickerham, D.L., Fisher, B., Wolmark, N., Bryant, J., Costantino, J., Bernstein, L. and Runowicz, C.D. (2002) Association of Tamoxifen and Uterinesarcoma. Journal of Clinical Oncology, 20, 2758-2760.

[9] Hassini, A., Khemiri, B., Sfar, E., Chelly, D., Chennoufi, M.B. and Chelly, H. (2006) Sarcomes Utérins: Aspects Cliniques et thérapeutiques: A propos de 10 cas. Journal de Gynécologie Obstétrique et Biologie de la Reproduction, 35, 348-355.

[10] Reichardt, P. (2012) The Treatment of Uterinesarcomas. Annals of Oncology, 23, x151-x157. http://dx.doi.org/10.1093/annonc/mds359

[11] Nam, J.H. (2011) Surgical Treatment of Uterinesarcoma. Best Practice \& Research Clinical Obstetrics \& Gynaecology, 25, 751-760. http://dx.doi.org/10.1016/j.bpobgyn.2011.05.009

[12] Le, T. (2001) Adjuvant Pelvicradiotherapy for Uterine Carcinosarcoma in a High Risk Population. European Journal of Surgical Oncology, 27, 282-285. http://dx.doi.org/10.1053/ejso.2000.1104

[13] Galaal, K., Godfrey, K., Naik, R., Kucukmetin, A. and Bryant, A. (2013) Adjuvant Radiotherapy and/or Chemotherapy after Surgery for Uterine Carcinosarcoma. Cochrane Database of Systematic Reviews, 2.

[14] Kaur, K., Kaur, P., Kaur, A. and Singla, A. (2014) Uterine Leiomyosarcoma: A Case Report. Journal of Midlife Health, 5, 202-204. 